\title{
A PRECIPITAÇÂO E SUA INFLUÊNCIA NA QUANTIDADE E QUALIDADE DA ÁGUA DA BACIA DO CÓRREGO BOM JARDIM, BRASILÂNDIA/MS.
}

\section{Gustavo Henrique de Oliveira ${ }^{1}$}

\author{
André Luiz Pinto ${ }^{2}$ \\ Denivaldo Ferreira de Souza ${ }^{3}$
}

RESUMO: O presente trabalho tem o intuito de avaliar a influencia que um determinado quantitativo de precipitação exerce sob a qualidade e quantidade da água em uma bacia hidrográfica. Visando também ressaltar a importância da correlação entre esses elementos com os processos erosivos que modelam as paisagens compostas por elementos interdependentes como no caso da bacia do Córrego Bom Jardim, localizada dentro dos limites municipais de Brasilândia/MS. Na bacia ocorrem diversos tipos de processos erosivos tanto de âmbito laminar quanto linear que por sua vez transportam sedimentos das vertentes da bacia para o leito de seu canal principal modificando assim sua geometria e qualidade de suas águas. Nesse sentido objetivou-se mostrar a importância de uma análise detalhada do montante mensal e anual precipitado dentro de um sistema aberto que sofre interferências intra e interdependentes dos diferentes tipos de uso, ocupação e manejo da terra assim como evidenciar através de indicações, medidas na intenção de mitigar problemas de assoreamento através de práticas conservacionistas e de manutenção do uso e manejo da terra. Faz-se necessário então para essa compreensão a utilização da metodologia proposta por CHRISTOFOLETTI (1980); PINTO (1985) e PINTO et. al. (2010) para a mensuração do montante de sedimentos transportados em suspensão, assim como da metodologia sugerida por Lombardi Neto e Moldenhauer (1992), modificada por Bertoni e Lombardi Neto (2008) para a obtenção dos valores de erosividades da bacia.

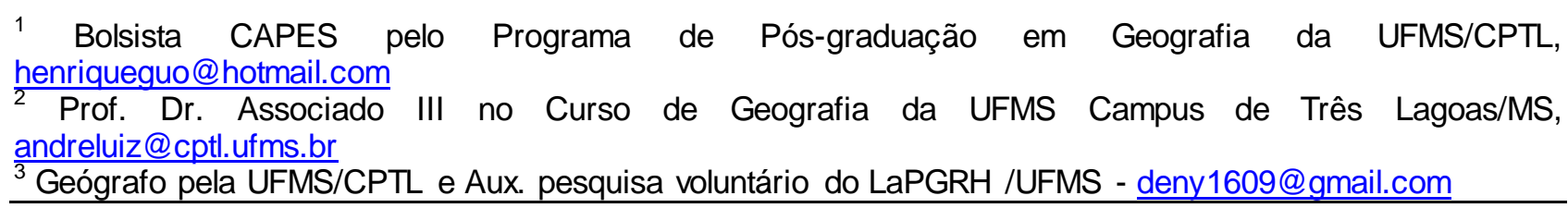

VIII Fórum Ambiental da Alta Paulista, v. 8, n.2, 2012, p. 321-337. 
Palavras-chave: Precipitação. Qualidade e Quantidade da Água. Transporte de Sedimentos em Suspensão.

\title{
1 INTRODUÇÃO
}

Após o estabelecimento da bacia hidrográfica como unidade de estudo e de planejamento, pela Agência Nacional de Águas, é crescente o número de pesquisadores que as adotam como recorte espacial para diagnóstico, análise e prognóstico. A grande vantagem que se encontra nesse âmbito está nas possibilidades de inter-relações entre os vários subsistemas que a constituem. Nesse sentido a bacia hidrográfica deve ser considerada como unidade básica de gestão dos recursos hídricos.

\begin{abstract}
A bacia hidrográfica, através da rede de drenagem fluvial, integra grande parte das relações causa-efeito que devem ser tratadas na gestão. Embora existam outras unidades político administrativas a serem consideradas, como os municípios, estados, regiões e países, essas unidades não apresentam necessariamente o caráter integrador da bacia hidrográfica, o que poderia tomar a gestão parcial e ineficiente caso fossem adotadas (SRH/MMA, 1997).
\end{abstract}

O dinamismo encontrado nos sistemas de bacias hidrográficas reflete de maneira extremamente simplificada as complexas interferências e correlações entre os elementos dos subsistemas naturais, construídos, socioeconômicos e produtivos, e a crescente interferência antrópica.

Como as bacias hidrográficas têm a ação das águas correntes controladas pelas formas de uso, ocupação e manejo da terra, além do que plantar e em que época e como se manejar esse uso, faz-se necessário, a adoção de práticas conservacionistas do solo, como o uso de curvas de nível, terraceamentos, caixas de retenção de águas, drenos, entre outras.

Onde predominam a pastagem cultivada, também se faz necessário a descompactação dos solos, sua calagem e renovação, e o manejo do gado, evitando-se que as áreas com maiores declividades e energia potencial do relevo recebam animais nos períodos mais chuvosos, com maiores potencialidades erosivas. Pois, segundo Bertoni e Lombardi Neto (1990, p. 45), a chuva é um dos fatores de maior importância 
para a erosão, sendo que sua intensidade, sua duração e a sua freqüência são as propriedades mais importantes para o processo erosivo.

Decorrente dessa preocupação e com o objetivo de auxiliar no ordenamento sustentável do território da bacia do Córrego Bom Jardim, em Brasilândia - MS o objetivo do presente trabalho vêm por meio de análises pluviométricas avaliar a influência do montante total precipitado durante os anos de 2009, 2010 e 2011 na bacia, com os dados de vazão, erosividade e competência fluvial de transporte de sedimentos em suspensão.

Pretende-se, portanto, através da correlação entre esses dados, contribuir, não apenas com a bacia do córrego Bom Jardim, como também subsidiar como referencial teórico metodológico para novos estudos, que visem um ordenamento preventivo do uso da terra pautado em dados de extrema importância em bacias e consecutivamente, a redução da perda de solo, produção, produtividade e da qualidade/quantidade de suas águas e melhoria da qualidade ambiental e de vida de seus habitantes.

\section{METODOLOGIA}

Para a execução da mensuração da competência de transporte fluvial em suspensão, foram utilizados os seguintes softwares e equipamentos Word 2007; Excel 2007; Autocad 2012, Corel Draw X5 e em campo, utilizou-se frascos plásticos de 500 ml, câmera digital fotográfica, GPS, Medidor de fluxo de água da Global Water FP 101, Estufa de Secagem, Conjunto de infiltração, Bomba à Vácuo, Balança de Precisão e Membrana Filtrante - Milipores, 47 mícrons, em ester de celulose. Para a análise físico-química dos parâmetros acima apontados embasou-se nas metodologias descritas por Pinto e Mauro (1985) e Pinto et. al. (2010).

Christofoletti (1981) salienta que o modo de utilização realizada nas áreas drenadas pela bacia hidrográfica repercute diretamente na composição química das águas, sendo que os dejetos, detritos e poluentes lançados pelas áreas urbanas e industriais causam modificações acentuadas na concentração de matéria dissolvida, 
repercutindo no balanço biológico das águas, nos processos de corrosão e nos de sedimentação.

Segundo Christofoletti (1980), os fatores hidrológicos, cujos mais importantes são a quantidade da cobertura vegetal influenciam a formação do material intemperizado na bacia hidrográfica e o carregamento desses materiais até os rios. O fluxo e o transporte de sedimentos constituem respostas aos processos e ao estado de equilíbrio atuante no sistema fluvial.

Par o monitoramento sazonal da bacia foram selecionados oito pontos ao longo do canal principal e dos afluentes, o córrego Aviação e o córrego Sete de Setembro, dispersos da nascente a sua foz, Figura 1. Para a coleta de amostras, utilizou-se frascos plásticos de $500 \mathrm{ml}$, de boca larga, os quais foram introduzidos nas áreas de maior velocidade do canal, até próximo ao fundo, sem que este afunda-se no leito arenoso, para receber o fluxo de sedimentos em suspensão, ao longo das estações de verão, outono, inverno e primavera, dos anos de 2009, 2010 e 2011. Conforme metodologia proposta por Pinto e Mauro (1985).

Em laboratório os frascos foram agitados e colocados, $100 \mathrm{ml}$, em conjunto de infiltração da milipore, com filtro de 4,7 microns de celulose, que em seguida foram a estufa de secagem por 24 horas a $60^{\circ} \mathrm{C}$ Logo após resfriarem os filtros foram pesados em balança de precisão e compará-los com o peso de seus respectivos filtros sem sedimentos, como os valores correspondem a $100 \mathrm{ml}$, estes foram convertidos para $\mathrm{m}^{3} \mathrm{e}$ calculados os valores conforme as vazões mensuradas durante os anos monitorados. 

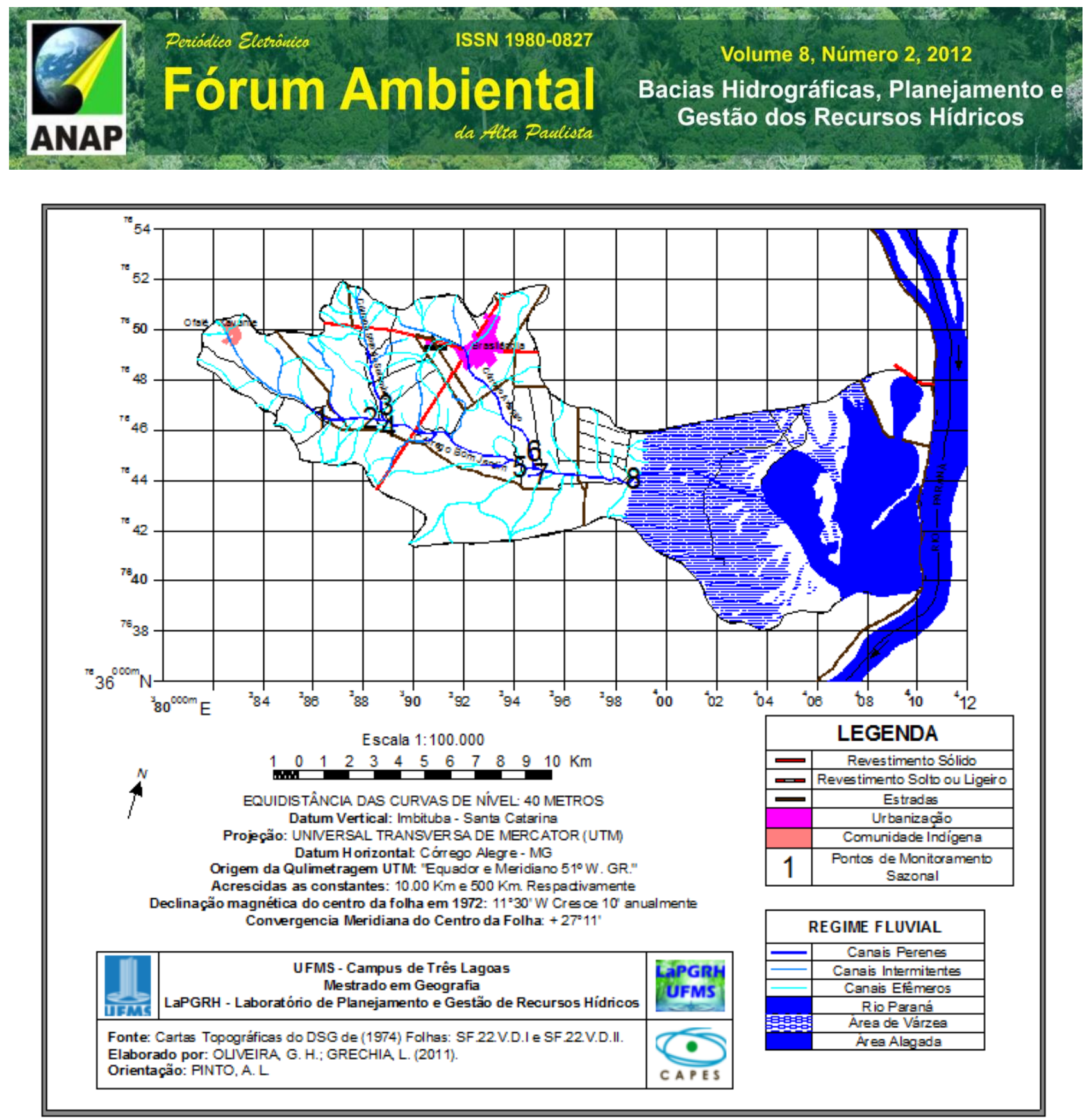

Figura 1: Mapa de Localização dos Pontos de Monitoramento na Bacia do Córrego Bom Jardim em Brasilândia/MS.

Segundo Bertoni e Lombardi Neto, a erosão:

é o processo de desprendimento e arraste acelerado das partículas do solo, causado pela água e pelo vento. Que dependem do tipo de material a ser transportado, da energia potencial do relevo, da profundidade do lençol freático, entre outras variáveis naturais e antrópicas (BERTONI; LOMBARDI NETO, 1990, p. 68).

Cunha (1997) ressalta que quando o processo erosivo é mais intenso, sendo mais veloz que a formação do solo, ocorre à erosão acelerada, chamada de erosão antrópica, caso tenha sido provocada pela ação humana.

Segundo Lal: 
Vários pesquisadores têm usado índices baseados em medidas rotineiras das propriedades do solo para avaliar a sua relativa suscetibilidade à erosão, tendo sido criados vários índices, como medidas de desagregação do solo ou de sua resistência à desagregação (LAL, 1988 p. 142).

O risco potencial erosivo de uma bacia significa identificar através da espacialização e quantificação, áreas que possivelmente tenham um potencial à erosão, seja ele baixo ou alto, para uma posterior avaliação. Como ressalta Carvalho e Pinto (2010, p. 667): "a identificação das áreas mais susceptíveis à erosão permite a possibilidade de melhor ordenamento do uso da terra."

Para as análises pluviométricas foram utilizados os dados de precipitação mensal e anual do triênio analisado, foram obtidos da estação meteorológica localizada nas coordenadas $20^{\circ} 47^{\prime} \mathrm{S}$ de Latitude e $51^{\circ} 42^{\prime} \mathrm{W}$ Longitude e $313 \mathrm{~m}$ de altitude, fornecidos pela empresa FIBRIA - MS Celulose Sul Mato-Grossense Ltda.

Os dados de vazão sazonal da bacia foram obtidos através de coletas de monitoramento realizadas em campo nas quatro estações de cada ano ao longo dos oito pontos de coletas ao longo da bacia do córrego Bom Jardim.

Os valores de erosividade foram obtidos pela fórmula sugerida por Lombardi Neto e Moldenhauer (1992), modificada por Bertoni e Lombardi Neto (2008), que consiste:

$$
E I=67,355\left(r^{2} / P\right)^{0,85}
$$

Onde:

$\mathrm{El}=$ índice médio de erosividade por um período anual (MJ.mm.ha ${ }^{-1} \cdot \mathrm{h}^{-1}$ )

$\mathrm{r}=$ precipitação média mensal $(\mathrm{mm})$

$\mathrm{P}=$ precipitação média anual $(\mathrm{mm})$

A variação do potencial erosivo ao longo do ano, também é importante para o planejamento das práticas conservacionistas a serem implementadas nas bacias hidrográficas, principalmente para a estimativa das perdas de solo.

Os dados referentes aos valores das normais de precipitação e El (índice de erosividade) foram citados conforme dados coletados em um intervalo de trinta anos e apresentados no plano de manejo para reserva do patrimônio particular da cisalpina, 
relatório encomendado pela empresa CESP em 2007. Enquanto que os dados normais de vazão, foram obtidos através de uma média tendo como base os três anos aqui pesquisados (2009, 2010 e 2011) que constituem banco de dados de pesquisa do Laboratório de Planejamento e Gestão de Recursos Hídricos (LaPGRH) da Universidade Federal de Mato Grosso do Sul - UFMS/CPTL.

\section{RESULTADOS E DISCUSSÃO}

Brasilândia está localizada na costa leste do estado do Mato Grosso do Sul, tendo como divisa ao norte o município de Três Lagoas e Água Clara, ao sul Santa Rita do Pardo e a leste com o rio Paraná que delimita a fronteira com o estado de São Paulo.

O município possui uma área de aproximadamente $5.000 \mathrm{Km}^{2}$, e situa-se entre as coordenadas geográficas $20^{\circ} 45^{\prime}$ e $21^{\circ} 34^{\prime}$ de latitude $S$ e $51^{\circ} 51^{\prime}$ e $52^{\circ} 56^{\prime}$ de longitude W, sendo essa uma região drenada por inúmeras micro-bacias que fluem para o Rio Paraná (PINTO, 2010), Figura 2.

O clima no município de Brasilândia possui duas estações bem definidas, uma estação chuvosa e outra seca, que segundo a classificação de Koppen é o Aw, definido como clima tropical úmido.

Segundo ATLAS MULTIRREFERENCIAL (1990) a área da bacia está disposta sobre terrenos cretáceos do Grupo Bauru, Formação Santo Anastácio, compostos por arenitos bastante porosos, facilmente desagregados, freqüentemente laterizados, onde repousam espesso e constante solo arenoso. Contudo Pinto (2010) ressalta que esta assenta-se sobre terrenos isótopos por arenitos dos Grupos Bauru (Formações Santo Anastácio e Adamantina) e Caiuá, respectivamente. Essas unidades litoestratigráficas caracterizam-se por alta porosidade e permeabilidade e a grande facilidade de desagregação. 

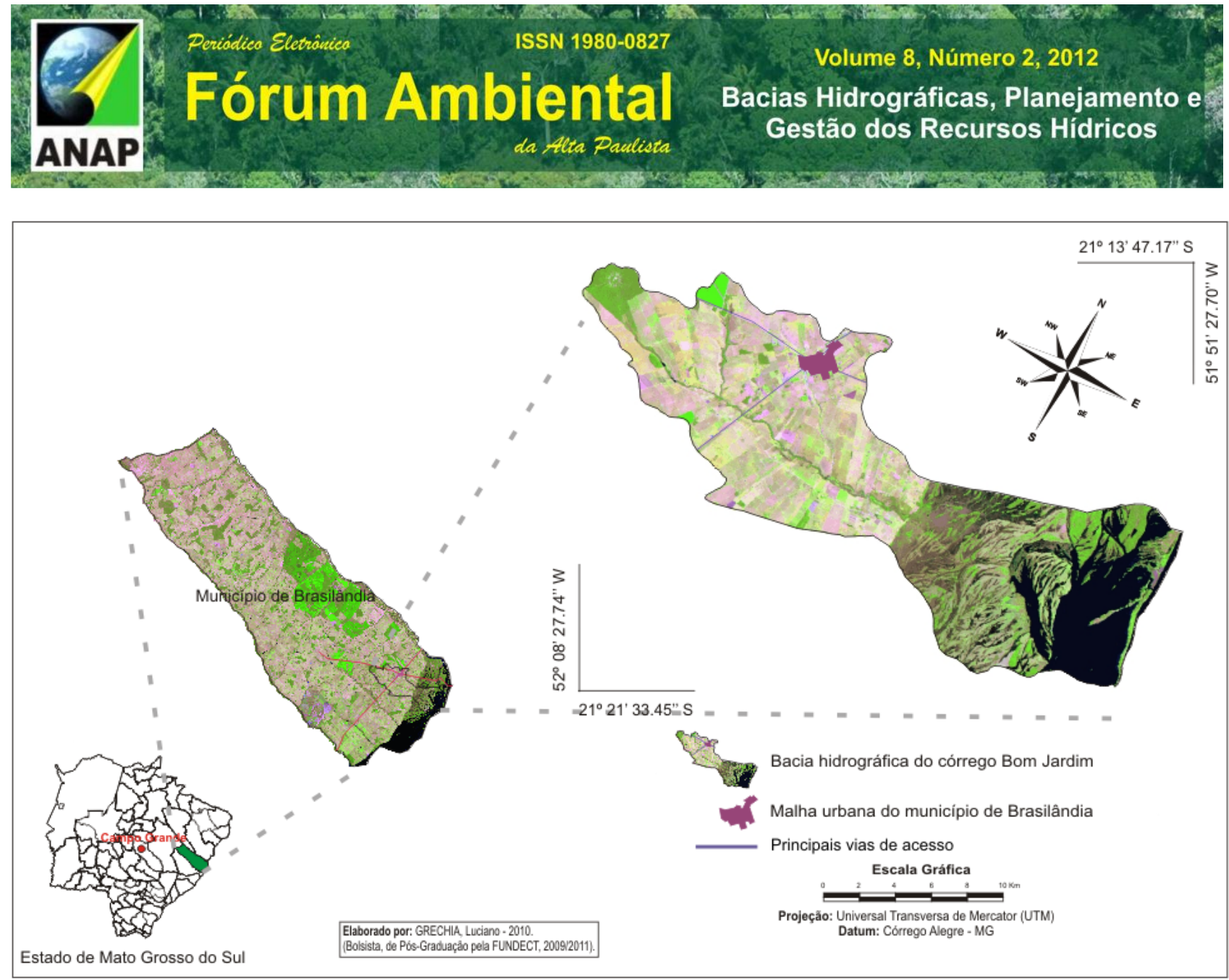

Figura 2: Mapa de localização da bacia do Córrego Bom Jardim no município de Brasilândia/MS.

A bacia por sua vez compreende-se por estar localizada em um meio físico ímpar, pois, suas nascentes encontram-se dentro da reserva indígena dos Ofayé-Xavante em meio a uma paisagem preservada por se tratar de uma reserva. Sua foz é marcada pela delimitação da Reserva Particular do Patrimônio Natural - RPPN Cisalpina da CESP (Companhia Energética de São Paulo) que por se tratar de um relevo extremamente acidentado, acabou por ser inundado devido à construção da UHE de Porto Primavera.

A tabela 1 apresenta um modelo analítico dos dados das normais de precipitação, vazão e erosividade, os quais foram por sua vez correlacionados com os mesmos tipos de dados porém dos anos que constituem o triênio de 2009, 2010 e 2011, obtendo assim os valores das diferenças ou desvios entre cada ano e os valores das normais. Esses desvios permitem uma análise simplificada e ao mesmo tempo detalhada dos dados pluviométricos de uma bacia, podendo os mesmo facilmente serem correlacionados com outros tipos de dados, mostrando assim uma alteração qualitativa ou física da paisagem. 


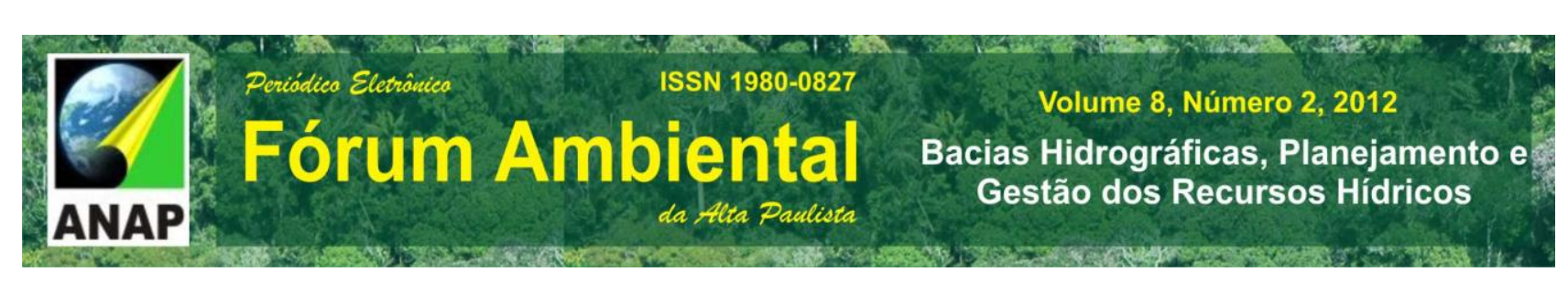

Tabela 1: Dados de precipitação, vazão e erosividade da bacia do córrego Bom Jardim, Brasilândia/MS, Brasil.

\begin{tabular}{|c|c|c|c|c|c|c|c|c|c|c|c|c|c|c|c|c|c|c|c|c|c|}
\hline \multirow[b]{2}{*}{ Mês } & \multicolumn{3}{|c|}{ Normais } & \multicolumn{6}{|c|}{2009} & \multicolumn{6}{|c|}{2010} & \multicolumn{6}{|c|}{2011} \\
\hline & $\begin{array}{c}\mathrm{P} \\
\mathrm{mm} \\
\end{array}$ & \begin{tabular}{c|} 
Vazão \\
m³/s $^{2}$
\end{tabular} & EI & $\begin{array}{c}\mathrm{P} \\
\mathrm{mm}\end{array}$ & \begin{tabular}{|c|} 
Desvio \\
$\mathrm{mm}$ \\
\end{tabular} & \begin{tabular}{|c|} 
Vazão \\
$m^{3} / s$ \\
\end{tabular} & $\begin{array}{c}\text { Desvio } \\
\mathrm{m}^{3} / \mathrm{s} \\
\end{array}$ & EI & Desvio & $\begin{array}{c}\mathrm{P} \\
\mathrm{mm} \\
\end{array}$ & $\begin{array}{c}\text { Desvio } \\
\mathrm{mm}\end{array}$ & $\begin{array}{c}\text { Vazão } \\
\mathrm{m}^{3} / \mathrm{s} \\
\end{array}$ & \begin{tabular}{|c|} 
Desvio \\
$\mathrm{m}^{3} / \mathrm{s}$ \\
\end{tabular} & EI & Desvio & $\begin{array}{c}\mathrm{P} \\
\mathrm{mm} \\
\end{array}$ & $\begin{array}{c}\text { Desvio } \\
\mathrm{mm} \\
\end{array}$ & \begin{tabular}{|c|} 
Vazão \\
$m^{3} / \mathrm{s}$ \\
\end{tabular} & \begin{tabular}{|c|} 
Desvio \\
$\mathrm{m}^{3} / \mathrm{s}$ \\
\end{tabular} & $\mathrm{EI}$ & Desvio \\
\hline JAN & 200,00 & $x$ & $1.379,00$ & 149,10 & 50,90 & $x$ & $x$ & 626,08 & 752,92 & 449,70 & 249,70 & $x$ & $x$ & $5.223,98$ & $3.844,98$ & 218,80 & 18,80 & $x$ & $x$ & $1.397,02$ & 18,02 \\
\hline FEV & 128,00 & $x$ & 963,00 & 196,10 & 68,10 & $x$ & $x$ & 997,54 & 34,54 & 180,10 & 52,10 & $\mathrm{x}$ & $x$ & $1.102,57$ & 139,57 & 101,50 & 26,50 & $x$ & $\mathrm{x}$ & 378,54 & 584,46 \\
\hline MAR & 197,00 & $x$ & $1.330,00$ & 182,90 & 14,10 & $x$ & $x$ & 886,10 & 443,90 & 118,50 & 78,50 & $\mathrm{x}$ & $x$ & 541,19 & 788,81 & 458,50 & 261,50 & $x$ & $x$ & $4.913,58$ & $3.583,58$ \\
\hline VER & 525,00 & 0,40 & $3.672,00$ & 528,10 & 3,10 & 0,18 & 0,22 & $2.509,72$ & $1.162,28$ & 748,30 & 223,30 & 0,18 & 0,22 & $6.867,74$ & $3.195,74$ & 778,80 & 253,80 & 0,83 & 0,43 & $6.689,14$ & $3.017,14$ \\
\hline $\mathrm{ABR}$ & 46,00 & $\mathrm{x}$ & 406,00 & 3,80 & 42,20 & $x$ & $x$ & 1,22 & 404,78 & 63,80 & 17,80 & $x$ & $x$ & 188,90 & 217,10 & 70,90 & 24,90 & $\mathrm{x}$ & $\mathrm{x}$ & 205,69 & 200,31 \\
\hline JUN & 19,00 & $x$ & 252,00 & 41,30 & 22,30 & $x$ & $x$ & 70,60 & 181,40 & 2,90 & 16,10 & $x$ & $x$ & 0,99 & 251,01 & 21,10 & 2,10 & $x$ & $\mathrm{x}$ & 26,21 & 225,79 \\
\hline OUT & 166,00 & 0,57 & $1.499,00$ & 119,30 & 46,70 & 0,51 & 0,06 & 262,98 & $1.236,02$ & 102,90 & 63,10 & 0,49 & 0,08 & 261,97 & $1.237,03$ & 96,10 & 69,90 & 0,71 & 0,14 & 233,52 & $1.265,48$ \\
\hline JUL & 25,00 & $x$ & 318,00 & 30,80 & 5,80 & $x$ & $x$ & 42,88 & 275,12 & 0,00 & 25,00 & $x$ & $x$ & 0,00 & 318,00 & 0,50 & 24,50 & $x$ & $x$ & 0,05 & 317,95 \\
\hline AGO & 53,00 & $\mathrm{x}$ & 501,00 & 76,40 & 23,40 & $x$ & $\mathrm{x}$ & 200,90 & 300,10 & 0,00 & 53,00 & $\mathrm{x}$ & $x$ & 0,00 & 501,00 & 3,30 & 49,70 & $x$ & $x$ & 1,19 & 499,81 \\
\hline SET & 55,00 & $x$ & 511,00 & 135,20 & 80,20 & $x$ & $x$ & 530,13 & 19,13 & 67,50 & 12,50 & $\mathrm{x}$ & $x$ & 207,90 & 303,10 & 14,50 & 40,50 & $x$ & $x$ & 13,85 & 497,15 \\
\hline INV & 133,00 & 0,68 & $1.330,00$ & 242,40 & 109,40 & 0,78 & 0,10 & 773,91 & 556,09 & 67,50 & 65,50 & 0,37 & 0,31 & 207,90 & $1.122,10$ & 18,30 & 114,70 & 0,88 & 0,20 & 15,09 & $1.314,91$ \\
\hline OUT & 180,00 & $x$ & $1.206,06$ & 154,40 & 25,60 & $x$ & $x$ & 664,39 & 541,67 & 83,90 & 96,10 & $\mathrm{x}$ & $x$ & 300,90 & 905,16 & 123,40 & 56,60 & $x$ & $x$ & 527,66 & 678,40 \\
\hline DEZ & 192,00 & $x$ & $1.297,63$ & 291,60 & 99,60 & $x$ & $x$ & $1.958,21$ & 660,58 & 123,90 & 68,10 & $\mathrm{x}$ & $\mathrm{x}$ & 583,79 & 713,84 & 162,60 & 29,40 & $x$ & $x$ & 843,39 & 454,24 \\
\hline PRI & 572,00 & 0,80 & $3.882,69$ & 723,90 & 151,90 & 0,92 & 0,12 & $4.426,99$ & 544,30 & 291,20 & 280,80 & 0,51 & 0,29 & $1.182,55$ & $2.700,14$ & 458,50 & 113,50 & 0,97 & 0,17 & $2.303,58$ & $1.579,11$ \\
\hline Total & $1.396,00$ & 2,43 & $10.383,69$ & $1.613,70$ & 217,70 & 2,39 & 0,05 & $7.973,60$ & $2.410,09$ & \begin{tabular}{|l|}
$1.209,90$ \\
\end{tabular} & 186,10 & 1,55 & 0,88 & $8.520,16$ & $1.863,53$ & $1.351,70$ & 44,30 & 3,39 & 0,96 & $9.241,33$ & $1.142,36$ \\
\hline Média & 116,33 & 0,20 & 865,31 & 134,48 & $x$ & 0,20 & $x$ & 664,47 & $x$ & 100,83 & $x$ & 0,13 & $x$ & 710,01 & $x$ & 112,64 & $x$ & 0,28 & $x$ & 770,11 & $x$ \\
\hline
\end{tabular}

VIII Fórum Ambiental da Alta Paulista, v. 8, n.2, 2012, p. 321-337. 


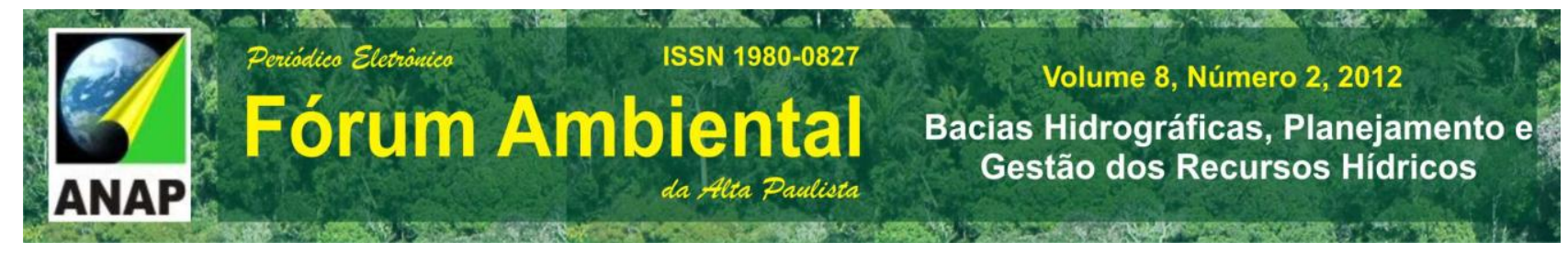

Onde:

P - Precipitação $(\mathrm{mm})$

EI - Índice de Erosividade (MJ.mm.ha ${ }^{-1} \cdot h^{-1}$ )

VER - Total da estação de Verão

OUT - Total da estação de Outono

INV - Total da estação de Inverno

PRI - Total da estação de Primaver 
Comparando ano a ano com os valores estabelecidos pelas normais dos três fatores aqui analisados (precipitação, vazão e erosividade), nota-se uma interdependência entre cada um deles.

Ainda focando na tabela acima, é nítido que perante as normais, referindo-se aos Índices de Erosividade, durante os três anos, esse valor tem ficado abaixo do valor normal que é de 10.383,69 MJ.mm.ha ${ }^{-1} \cdot h^{-1}$, porém esse índice de erosividade vem aumentando a cada ano como visto em 2009 com 7.973,60 MJ.mm.ha ${ }^{-1} \cdot h^{-1}, 2010$ com 8.520,16 MJ.mm.ha' ${ }^{-1} \cdot h^{-1}$ e 2011 com um valor de 9.241,33 MJ.mm.ha ${ }^{-1} \cdot h^{-1}$. O que por sua vez, são valores que dependem diretamente do quantitativo precipitado na bacia.

A precipitação (Figura 3) durante esses três anos teve seu comportamento de forma atípica, pois segundo os dados das normais climatológicas, contradiz o padrão de primavera mais chuvosa que o verão. Na estação de primavera o montante normal precipitado é de $572 \mathrm{~mm}$ de chuva enquanto que no verão esse número atinge o valor de $525 \mathrm{~mm}$, assim sendo, como mostra o gráfico da figura abaixo, o único ano ao qual a precipitação se portou como nas normais foi o ano de 2009.

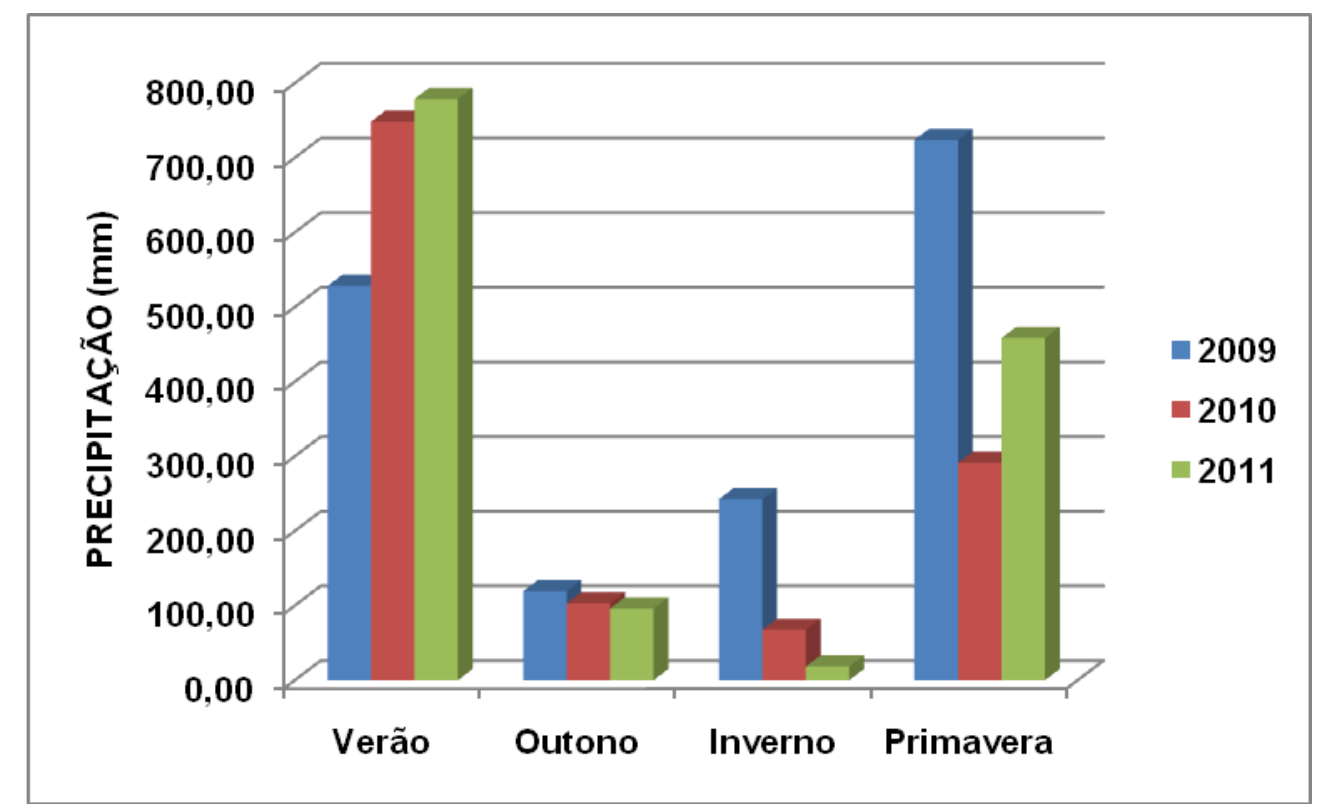

Figura 3: Variação da precipitação sazonal entre os anos de 2009, 2010 e 2011 da bacia do córrego Bom Jardim, Brasilândia/MS.

Observa-se então que na correlação dos dados normais de precipitação com os dados de erosividade (Tabela 1) que a estação do ano primavera, a mais chuvosa é 
também a que maior potencial erosivo tem, 3.882,69 MJ.mm.ha ${ }^{-1} \cdot \mathrm{h}^{-1}$, que representa $37,27 \%$ do total do potencial erosivo da Bacia. A estação do inverno, marcada pela reduzida precipitação e erosividade potencial, concentrando apenas 12,83\% da precipitação, não engloba o mês de menor potencial erosivo. Cabe ao outono, no mês de junho, ser o mais seco e o de menor potencial erosivo, com apenas $252 \mathrm{~mm} / \mathrm{ha}$, representando apenas $2,43 \%$ do total do potencial erosivo da bacia.

Dos três anos aqui analisados, nota-se que em relação aos índices potenciais erosivos nas quatro estações de cada ano, somente o ano de 2009 seguiu 0 comportamento dos índices normais na bacia.

Portanto, a Bacia tem maior potencial erosivo no período mais chuvoso, que se estende de outubro a março, sobre tudo na primavera. Tendo seu potencial erosivo acrescido por refletir grande concentração de chuvas após a estação de estiagem, que se prolonga de abril a setembro, interagindo com solos aerados, ressecados e muitas vezes arados ou queimados, ocupados por pastagens mal manejadas, facilitando em muito a ação erosiva das águas correntes.

Analisando os valores de vazão obtidos em campo, em cada estação do ano durante o triênio, apresentados na tabela 2 e figura 4 nota-se que o ano de 2011 teve um elevado índice de vazão, sobressaindo-se não somente quanto aos anos anteriores de 2009 e 2010 mas também superando o valor das normais de vazão que é de 2,43m³/s na somatória das quatro estações

Tabela 2: Vazão sazonal dos anos de 2009, 2010 e 2011 da bacia do córrego Bom Jardim, Brasilândia/MS, em $\mathrm{m}^{3} / \mathrm{s}$.

\begin{tabular}{c|r|r|r}
\hline Estação do ano & \multicolumn{1}{|c|}{$\mathbf{2 0 0 9}$} & \multicolumn{1}{|c|}{$\mathbf{2 0 1 0}$} & \multicolumn{1}{c}{$\mathbf{2 0 1 1}$} \\
\hline Verão & 0,18 & 0,18 & 0,83 \\
\hline Outono & 0,51 & 0,49 & 0,71 \\
\hline Inverno & 0,78 & 0,37 & 0,88 \\
\hline Primavera & 0,92 & 0,51 & 0,97 \\
\hline TOTAL & $\mathbf{2 , 3 8}$ & $\mathbf{1 , 5 5}$ & $\mathbf{3 , 3 9}$ \\
\hline
\end{tabular}

Org.: OLIVEIRA (2012). 


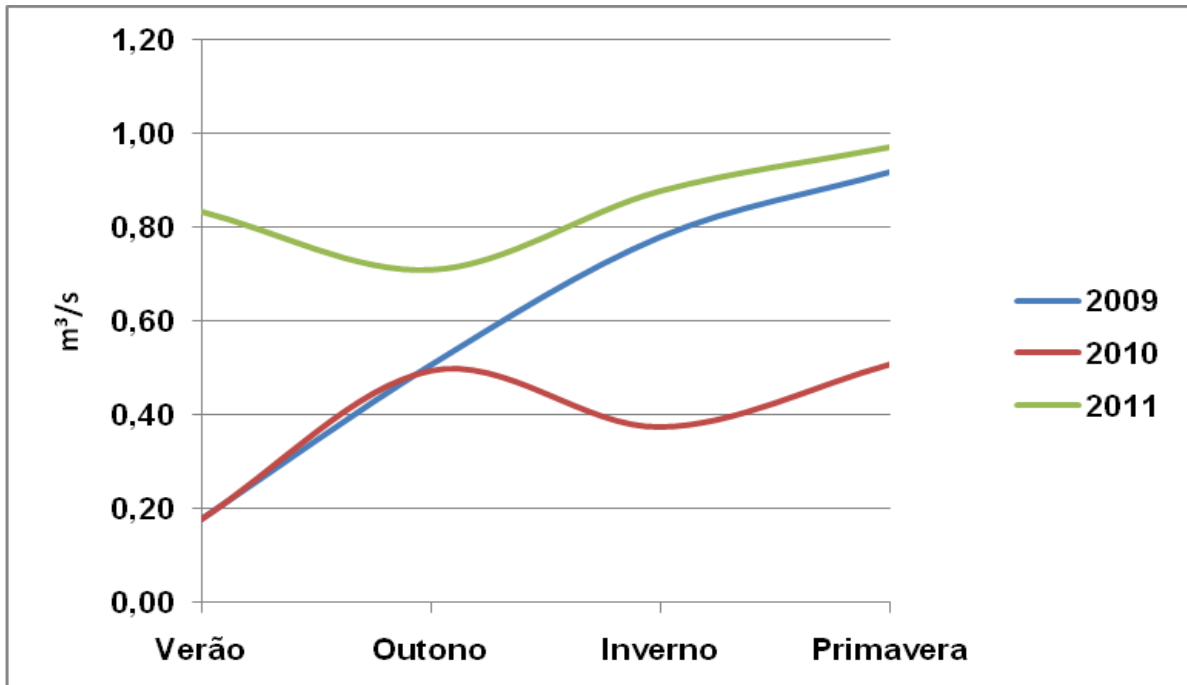

Figura 4: Variação da vazão sazonal entre os anos de 2009, 2010 e 2011 da bacia do córrego Bm Jardim, Brasilândia/MS.

Já a competência fluvial de transporte de sedimentos em suspensão como mostra a tabela 3 e o gráfico da figura 5 , representa o quantitativo total de sedimentos transportados em suspensão pela bacia, mensurados durante os anos de 2009, 2010 e 2011 nos oito pontos de coleta.

Tabela 3: Competência de fluvial de transporte de sedimentos em suspensão dos anos de 2009, 2010 e 2011 da bacia do córrego Bom Jardim, Brasilândia/MS.

\begin{tabular}{c|r|r|r}
\hline Estação do ano & $\mathbf{2 0 0 9}$ (ton) & $\mathbf{2 0 1 0}$ (ton) & $\mathbf{2 0 1 1}$ (ton) \\
\hline Verão & 25,38 & 140,45 & 221,22 \\
\hline Outono & 68,33 & 74,17 & 55,71 \\
\hline Inverno & 62,28 & 49,00 & 220,39 \\
\hline Primavera & 36,55 & 176,09 & 86,95 \\
\hline TOTAL & $\mathbf{1 9 2 , 5 4}$ & $\mathbf{4 3 9 , 7 1}$ & $\mathbf{5 8 4 , 2 7}$ \\
\hline
\end{tabular}

Org.: OLIVEIRA (2012). 


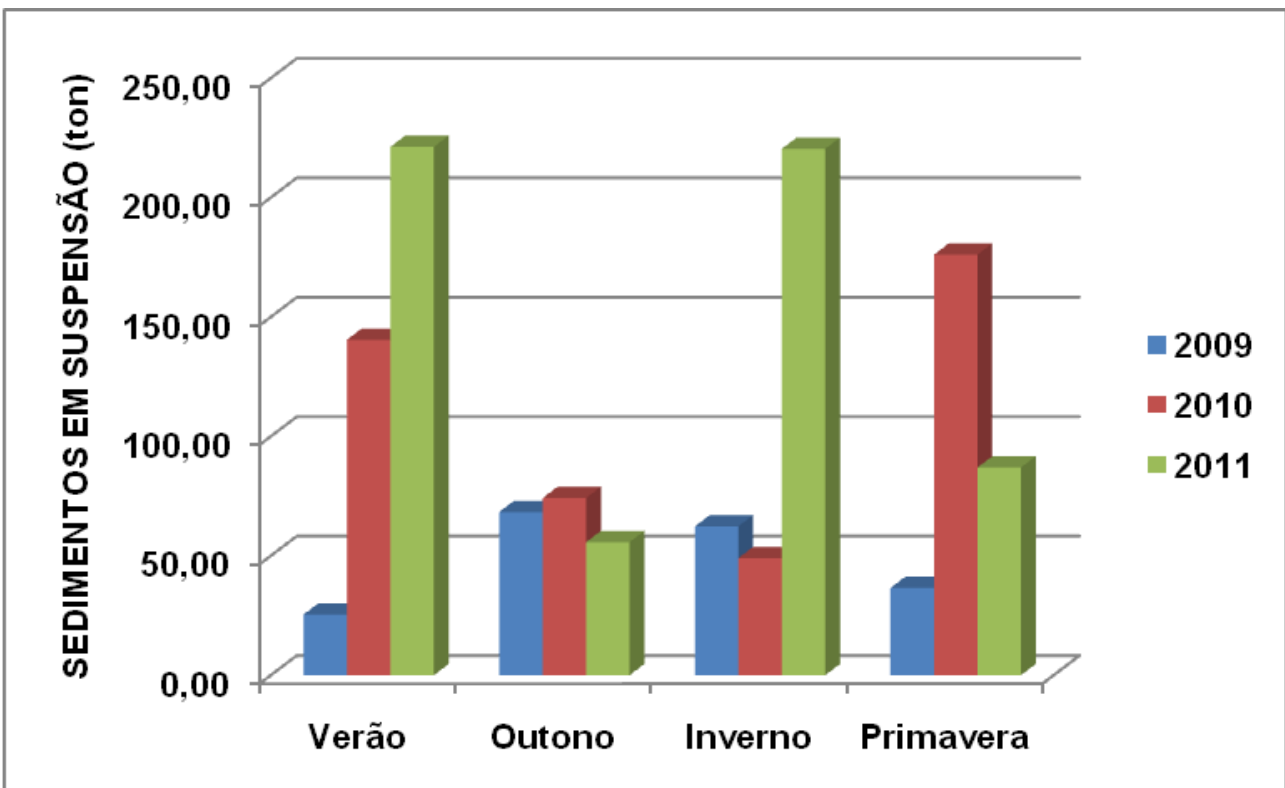

Figura 5: Quantitativo total de sedimentos transportados em suspensão durante os anos de 2009, 2010 e 2011, em toneladas por estações.

Durante o ano de 2009 o valor de material particulado transportado em suspensão pela bacia foi o menor valor obtido dentre os três anos, 192,54 toneladas, já em 2010 o valor mensurado chegou a 439,71 toneladas durante o ano todo, enquanto que o ano posterior, em 2011 o valor mensurado foi ainda maior, chegando a 584,27 toneladas. Há de se ressaltar a correlação entre os valores de vazão que, a pesar de terem variado pouco quanto a sua média de um ano para outro acarretou num aumento do transporte fluvial em 32,88\%. Muito maior que a variação pluviométrica nestes anos, pois em 2010 essa variação foi de $1.209,9 \mathrm{~mm}$ e em 2011 , de $1.351,5 \mathrm{~mm}$, variação de $11,70 \%$, mostrando a influencia do uso, ocupação e manejo da terra.

\section{CONSIDERAÇÕES FINAIS}

Diante dos dados analisados no triênio 2009-2011, conclui-se portanto, que a concentração das precipitações proporciona maior potencial erosivo, como mostra o modelo proposto por Bertoni e Lombardo Neto (1990), e que possui alta correlação com 


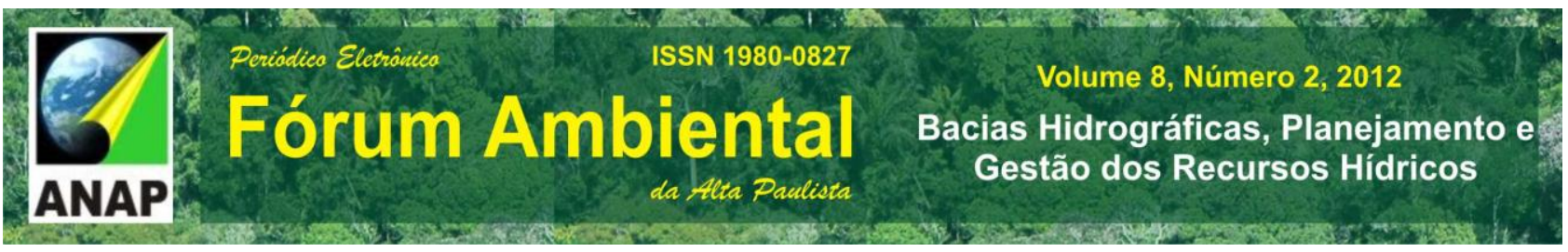

os dados do montante de sedimentos particulados transportados em suspensão pelo canal da bacia do córrego Bom Jardim e sua respectiva vazão mensurada.

O modelo de Bertoni e Lombardo Neto (1990) proporciona informações importantes para o planejamento do manejo, não só da pastagem, entendendo-a como cultura, como também, dos rebanhos de gado bovino - nelore, sendo indicado que nos meses chuvosos o solo deva estar provido pela vegetação, no sentido de conter o impacto da água corrente que proporcionam fortes dissecações, transporte e deposições ao longo das vertentes e da bacia.

Ademais o escoamento superficial que lava a superfície da terra e transporta para a rede de drenagem enorme quantidade de sedimentos e diversos elementos biológicos e químicos, alteram a composição da água e compromete sua qualidade para o consumo humano e animal.

Além do manejo inadequado do gado criado extensivamente com acesso ao canal fluvial, que constitui a única opção para sedentação animal, há falta de práticas conservacionistas de uso e ocupação da terra, como implantação das curvas de nível para a contenção do escoamento superficial, cercamento e reflorestamento da mata ciliar nativa e conscientização da comunidade local no sentido de preservar o solo para um posterior aumento na quantidade e na qualidade da água, não só com uma visão local, mas partindo do particular para o geral.

Para uma contensão ou minimização do carreamento de material particulado em suspensão que assoream as calhas dos canais de bacias hidrográfica, bem como a redução de processos erosivos próximos ou em áreas de preservação como a unidade de conservação RPPN Cisalpina, recomenda-se a elaboração de um Plano de Manejo e Gestão para a bacia como um todo. Fazendo-se necessário o emprego de práticas conservacionistas de uso, ocupação e manejo da terra, como curvas de nível, caixas de retenção nas estradas próximas aos cursos d'água, recomposição das matas ciliares e preservação das nascentes principais e afluentes.

Conclui-se, portanto que a metodologia utilizada, quando trabalhada para anos que condizem com as normais climáticas é extremamente eficiente, tanto para a avaliação de erosividade potencial, quanto ao quantitativo pluviométrico e mensuração da carga de sedimentos fluviais em suspensão. A erosividade potencial do relevo mostrou-se eficiente, 
porém depende na prática de inúmeras variáveis: precipitação, uso, ocupação e manejo da terra, profundidade e variação no nível freático, composição dos materiais inconsolidados, as quais devem ser levadas em consideração com restrições, dependendo da característica dos ecossistemas. A dificuldade de se colocar esta metodologia em prática, é que as Prefeituras Municipais não dispõem de informações de seus municípios em escala de detalhamento para seus planos, diretores de manejo e gestão e também pela pouca importância dada a estes tipos de pesquisas que são geradas a baixo custo e com certa facilidade.

\section{REFERÊNCIAS}

ARAUJO, G. H. S.; ALMEIDA, J.R. de; GUERRA, A. J. T. Gestão Ambiental de Áreas Degradadas. São Paulo - SP. Bertrand Brasil, 2005, p. 24.

BERTONI, J. \& LOMBARDI NETO, F. Conservação do solo. 6.ed. São Paulo, Ícone. 2008. 355p.

BRASIL. Ministério do Meio Ambiente. Secretaria dos Recursos Hídricos e da Amazônia Legal. Política Nacional de Recursos Hídricos. Brasília, DF, 1997.

CHRISTOFOLLETTI, A. Geomorfologia. São Paulo, Edgard Blücher, 2ª edição, 1980.

CHRISTOFOLETTI, A. Geomorfologia fluvial. São Paulo: Edgard Bluncher, 1981

CARVALHO, E. M.; PINTO, S. A. F. Avaliação do potencial natural de erosão da bacia do córrego João Dias,Aquidauana, MS. In: 3o Simpósio de Geotecnologias no Pantanal.Cáceres, MT. Embrapa Informática Agropecuária/INPE, 2010. P. 666 - 675.

CUNHA, C. M. L. Quantificação e mapeamento das perdas de solo por erosãocom base na malha fundiária. Rio Claro: Instituto de Geociências e Ciênciasxatas, UNESP, 1997.

LAL, R. Erodibility and erosivity. In: LAL, R. et al. Soil erosion research methods. Soil and Water Conservation Society.Washington, 1988. p. 141-160. 
LOMBARDI NETO, F. e MOLDENHAUER, W,C. Erosividade da chuva - sua distribuição e relação com perdas de solo em Campinas, SP.Encontro Nacional de Pesquisas sobre conservação do Solo.51, n.2, Campinas, 1992. Anais..., Campinas, Sociedade Brasileira de Ciência do Solo, 1992. p. 189-196..

MATO GROSSO DO SUL Atlas Multirreferêncial. Secretaria Estadual de Planejamento e Coordenação Geral. Geologia. Campo Grande, 1990, p.10.

PINTO, A. L. ; A importancia do Ribeirão Claro para o Abastecimento de água da cidade de Rio Claro-SP. In:Geografia Teorética-vol.15 1985.

PINTO, A. L.; LORENZ S., J. L.; FERREIRA, A. G.: BASSO, P. M.; GRECHIA, L.: OLIVEIRA, G. H.; PEREIRA, G. A. Subsidio Geológico/Geomorfológico ao ordenamento do uso, ocupação e manejo do solo, visando a redução da perda de solo e a recuperação da qualidade das águas superficiais da Bacia do Córrego Bom Jardim, Brasilândia/MS. Relatório Final FUNDECT/MS. UFMS. Três Lagoas, 2010, 242p.

PLANO DE MANEJO PARA RESERVA CISALPINA. Relatório encomendado pela CESP. Departamento de Meio Ambiente. São Paulo, outubro de 2007, 173 p.

TOY, T.J.; FOSTER, G.R. \& RENARD, K.G. Soil erosion: Processes, prediction, measurement, and control. New York, Willey, 2002. 338p. 